\title{
PENINGKATAN KEKUATAN GESER TANAH DENGAN MENGGUNAKAN CERUCUK
}

\author{
Hendri Gusti Putra ${ }^{1}$, Abdul Hakam ${ }^{2}$, Nova Yusri ${ }^{3}$
}

\begin{abstract}
ABSTRAK
Tanah lempung merupakan jenis tanah yang memiliki kuat geser yang rendah sehingga akan menghadapi masalah apabila tanah lempung ini menerima beban yang cukup besar. Hal ini menyebabkan tanah lempung tidak bisa diberi beban yang besar. Cara untuk mengatasi masalah ini bisa dilakukan dengan memberi urugan di atas tanah lempung itu. Tapi cara ini memerlukan biaya yang besar. Salah satu alternatif lain untuk meningkatkan kekuatan geser tanah lempung adalah dengan memberikan cerucuk yang ditusukkan ke dalamnya. Penelitian ini ditujukan untuk mengetahui seberapa besar pengaruh penggunaan cerucuk terhadap kekuatan geser tanah lempung. Metode yang digunakan yaitu dengan membandingkan berbagai kombinasi cerucuk yang ditusukan ke dalam tanah lempung dan tanpa cerucuk. Percobaan di laboratorium dengan menggunakan alat compression machine untuk menentukan kekokohan tanah atau daya dukung dari tanah lempung itu. Cerucuk dipasang dengan berbagai variasi dimulai dari panjang cerucuk, penempatan cerucuk (vertikal maupun horizontal) dan jarak antar cerucuk. Dari hasil percobaan dapat disimpulkan bahwa penggunaan cerucuk dapat meningkatkan kekuatan geser pada tanah lempung. Semakin panjang cerucuk dan semakin dekat jarak antar cerucuk, semakin dapat meningkatkan kekuatan geser tanah lempung. Penelitian ini diharapkan dapat menjadi masukan guna mengetahui seberapa besar pengaruh penggunaan cerucuk untuk meningkatkan kekuatan geser tanah lempung.
\end{abstract}

Kata Kunci : tanah lempung, kekuatan geser, cerucuk.

\section{PENDAHULUAN}

\subsection{Latar Belakang}

Dalam suatu proyek, masalah tanah merupakan sesuatu yang mutlak perlu diperhatikan oleh para civil engineering. Sebelum melaksanakan suatu proyek, yang harus diketahui adalah karakteristik tanah yang seperti apa yang akan ditemui di lapangan nanti. Ini diperlukan untuk mengetahui langkah-langkah apa yang harus diambil nantinya sebelum terjadi hal-hal yang tidak diinginkan. Tanah lempung merupakan tanah yang mempunyai daya dukung dan kekuatan geser yang rendah, maka akan timbul masalah apabila jenis tanah ini menerima beban yang cukup besar. Hal ini tentunya tidak dikehendaki. Untuk perbaikannya memerlukan biaya yang cukup mahal. Pada penelitian ini, dicoba untuk melakukan perkuatan terhadap jenis tanah lempung tersebut dengan memberikan cerucuk yang ditusukan ke dalam tanah lempung itu.

\subsection{Tujuan dan Manfaat}

Tujuan penelitian ini adalah untuk mengetahui seberapa besar pengaruh penggunaan cerucuk terhadap kekuatan geser tanah lempung.

\footnotetext{
${ }^{1}$ Staf Pengajar Jurusan Teknik Sipil Fakultas Teknik Universitas Andalas, e-mail: hendrigp@ft.unand.ac.id

${ }^{2}$ Staf Pengajar Jurusan Teknik Sipil Fakultas Teknik Universitas Andalas, e-mail: ahakam@ft.unand.ac.id

${ }^{3}$ Mahasiswa Jurusan Teknik Sipil Fakultas Teknik Universitas Andalas
} 
Manfaat dari penelitian ini adalah untuk mengantisipasi masalah-masalah yang timbul pada tanah lempung dalam menerima beban yang cukup besar.

\subsection{Batasan Masalah}

- Penelitian ini menggunakan tanah lempung, dimana sampel tanah diambil dari lapangan dan dilakukan percobaan water content di laboratorium.

- Cerucuk yang digunakan berupa bambu yang mempunyai ukuran diameter $d=3 \mathrm{~mm}$ dan panjang $l=15 \mathrm{~cm}, 12,5 \mathrm{~cm}, 10 \mathrm{~cm}, 7,5 \mathrm{~cm}$.

- Contoh tanah dicetak dengan cetakan pipa yang berbentuk silinder (Ø $11 \mathrm{~cm}$, tinggi $22 \mathrm{~cm})$.

- Percobaan dilakukan dengan menggunakan unconfined strength machine.

\section{TINJAUAN PUSTAKA}

Parameter kuat geser tanah diperlukan untuk analisis-analisis daya dukung tanah, stabilitas lereng, dan tegangan dorong untuk dinding penahan tanah. Pemakaian cerucuk sebagai usaha untuk meningkatkan daya dukung tanah secara sederhana yang memiliki beberapa keunggulan antara lain biaya yang relatif murah, bahan mudah didapat, pelaksanaannya sederhana, mudah dikontrol serta waktu pelaksanaan yang singkat.

\section{METODOLOGI}

\subsection{Material Percobaan}

Pengambilan contoh tanah lempung dilakukan secara disturb yang diambil dari daerah Aia Pacah dengan menggunakan cangkul sampai kedalaman $\pm 0,5 \mathrm{~m}$.

\subsection{Pembuatan Benda Uji}

- Tanah dimasukkan ke dalam ember besar.

- Banyaknya tanah dalam ember harus bisa digunakan untuk mencetak sembilan contoh tanah.

- Dalam menuangkannya diusahakan tidak terdapat rongga.

- Setelah selesai dicetak, tanah dalam cetakan pipa dijenuhkan agar kadar air dalam cetakan tetap konstan.

- Contoh tanah diberi cerucuk dan langsung di tes dengan menggunakan alat unconfined strength test.

\subsection{Metode Percobaan}

\subsubsection{Tanpa Cerucuk}

Tanah lempung tanpa cerucuk dengan $\varnothing 11 \mathrm{~cm}$ dan tinggi $22 \mathrm{~cm}$ dites dengan alat unconfined strength test.

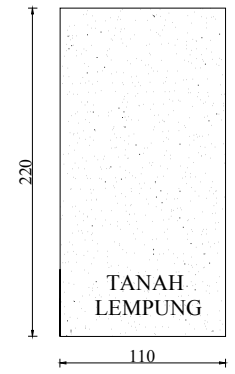

\section{Gambar 1. Tanah Lempung Tanpa Cerucuk}


Hendri Gusti Putra, Abdul Hakam, Nova Yusri

\subsubsection{Memakai Cerucuk}

\subsubsection{Cerucuk Vertical, terdiri atas :}

1). $\mathrm{CV} 150 ; 1.60$
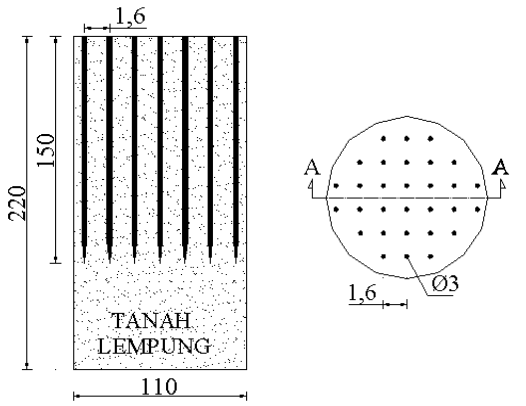

2). $\mathrm{CV} 125 ; 1.83$
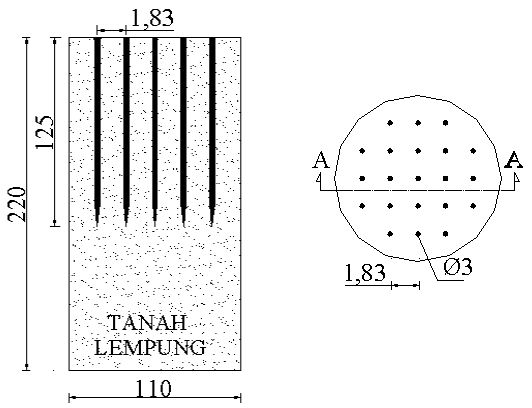

Gambar 3. Cerucuk Vertikal, Panjang Cerucuk

$12 \mathrm{~cm}$, Jarak antar Cerucuk 1,83 cm

3). $\mathrm{CV} 100 ; 2.20$
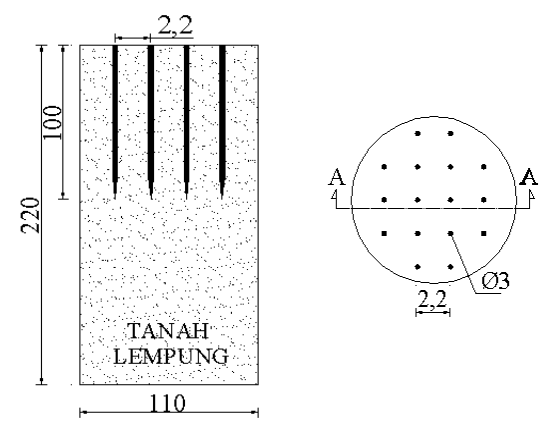

Gambar 2. Cerucuk Vertikal, Panjang Cerucuk $15 \mathrm{~cm}$, Jarak antar Cerucuk 1,60 cm

Gambar 4. Cerucuk Vertikal, Panjang Cerucuk $10 \mathrm{~cm}$, Jarak antar Cerucuk 2,20 cm

4). $\mathrm{CV} 75 ; 2.75$
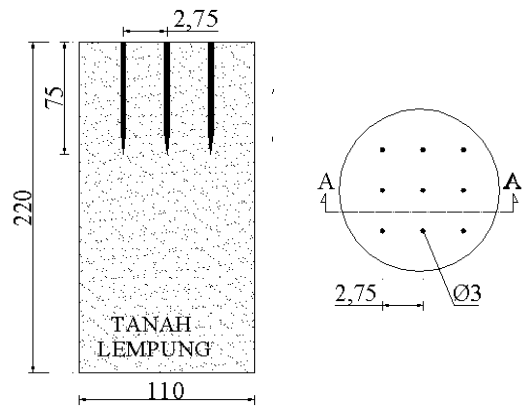

Gambar 5. Cerucuk Vertikal, Panjang Cerucuk 7,5 cm, Jarak antar Cerucuk 2,75 cm 
Tabel 1. Pola pemasangan Cerucuk dari Sisi Alas dengan Sudut Kemiringan $90^{\circ}$ dari Bidang Alas Tanah Lempung

\begin{tabular}{|c|c|c|c|}
\hline $\boldsymbol{d}(\mathbf{m m})$ & $\boldsymbol{l}(\mathbf{c m})$ & $\boldsymbol{s}(\mathbf{c m})$ & Jumlah Percobaan \\
\hline 3 & 15 & 1.60 & 3 \\
3 & 12.5 & 1.83 & 3 \\
3 & 10 & 2.20 & 3 \\
3 & 7.5 & 2.75 & 3 \\
\hline
\end{tabular}

Keterangan :

$$
\begin{aligned}
& l=\text { panjang cerucuk }(\mathrm{cm}) \\
& s=\text { jarak antar cerucuk }(\mathrm{cm}) \\
& d=\operatorname{diameter} \text { cerucuk }(\mathrm{cm})
\end{aligned}
$$

\subsubsection{Cerucuk Horizontal, terdiri atas :}

1). CHS $150 ; 2.75$ (5 lapis)
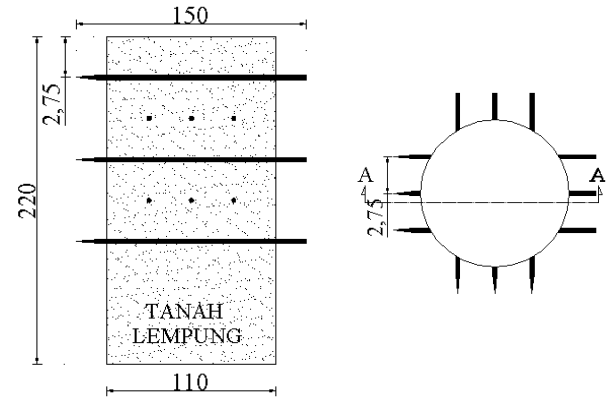

Gambar 6. Cerucuk Horizontal Silang, Panjang Cerucuk $15 \mathrm{~cm}$, Jarak antar Cerucuk 2,75 cm

2). CHS $125 ; 2.20$ (5 lapis)
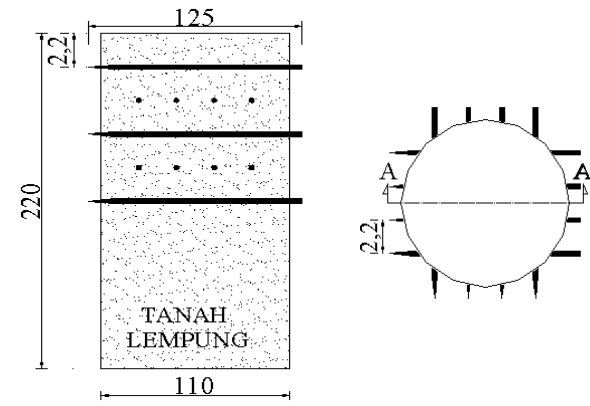

Gambar 7. Cerucuk Horizontal Silang, Panjang, Cerucuk $12.5 \mathrm{~cm}$, Jarak antar Cerucuk 2,20 cm

3). $\mathrm{CH} 150 ; 2.75$ (5 lapis)

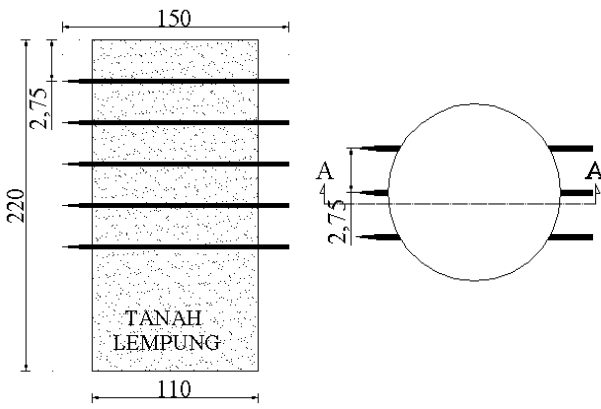

Gambar 8. Cerucuk Horizontal, Panjang Cerucuk15 cm, Jarak antar Cerucuk 2,75 cm 
4). $\mathrm{CH} 125 ; 2.20$ (5 lapis)

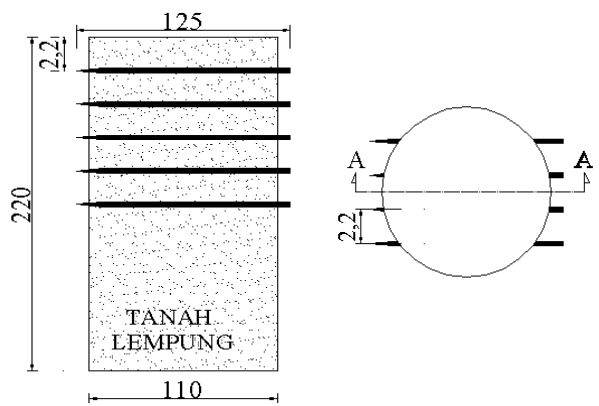

Gambar 9. Cerucuk Horizontal, Panjang Cerucuk 12,5 cm, Jarak antar Cerucuk 2,20 cm

Tabel 2. Pola Pemasangan Cerucuk Horizontal dipasang Bersilangan

\begin{tabular}{|c|c|c|c|c|}
\hline $\begin{array}{c}\boldsymbol{d} \\
(\mathbf{m m})\end{array}$ & $\begin{array}{c}\boldsymbol{I} \\
\mathbf{( c m )}\end{array}$ & $\begin{array}{c}\boldsymbol{s} \\
(\mathbf{m m})\end{array}$ & $\begin{array}{c}\text { Jumlah } \\
\text { Percobaan }\end{array}$ & $\begin{array}{c}\text { Jumah } \\
\text { Lapis }\end{array}$ \\
\hline 3 & 15,0 & 2,75 & 3 & 5 \\
\hline 3 & 12,5 & 2,20 & 3 & 5 \\
\hline
\end{tabular}

Tabel 3. Pola Pemasangan Cerucuk Horizontal dipasang Sejajar

\begin{tabular}{|c|c|c|c|c|}
\hline $\begin{array}{c}\boldsymbol{d} \\
(\mathbf{m m})\end{array}$ & $\begin{array}{c}\boldsymbol{I} \\
\mathbf{( c m )}\end{array}$ & $\begin{array}{c}\boldsymbol{s} \\
(\mathbf{m m})\end{array}$ & $\begin{array}{c}\text { Jumlah } \\
\text { Percobaan }\end{array}$ & $\begin{array}{c}\text { Jumah } \\
\text { Lapis }\end{array}$ \\
\hline 3 & 15,0 & 2,75 & 3 & 5 \\
\hline 3 & 12,5 & 2,20 & 3 & 5 \\
\hline
\end{tabular}

\subsection{Peralatan yang Digunakan}

Dalam pembuatan benda uji, maka peralatan yang digunakan adalah sebagai berikut :

a. Tanah lempung

Tanah lempung yang dipakai dalam percobaan ini diambil dari daerah Aia Pacah, dimana pengambilannya dilakukan secara disturb.

b. Ember besar

Ember besar digunakan untuk tempat pengadukan tanah lempung. Dipakai yang besar agar nantinya tanah lempung tersebut dapat dituangkan sekaligus ke dalam cetakan yang berjumlah sembilan buah.

c. Kayu pengaduk

Kayu pengaduk digunakan untuk menjaga agar campuran tanah lempung tersebut tetap rata.

d. Cerucuk

Cerucuk terbuat dari bambu dengan diameter $3 \mathrm{~mm}$ dengan panjang $15 \mathrm{~cm}$ dan $12,5 \mathrm{~cm}$ (Gambar 10), panjang $10 \mathrm{~cm}$ dan 7,5 $\mathrm{cm}$ (Gambar 11).

e. Cetakan silinder

Cetakan silender dengan diameter $11 \mathrm{~cm}$ dan tinggi $22 \mathrm{~cm}$. Dipakai untuk mencetak tanah yang sudah kita aduk agar berbentuk silinder (Gambar 12).

f. Unconfined strength test

Unconfined strength test adalah alat yang digunakan untuk mengetahui kekuatan geser dari sampel tanah (Gambar 13). 


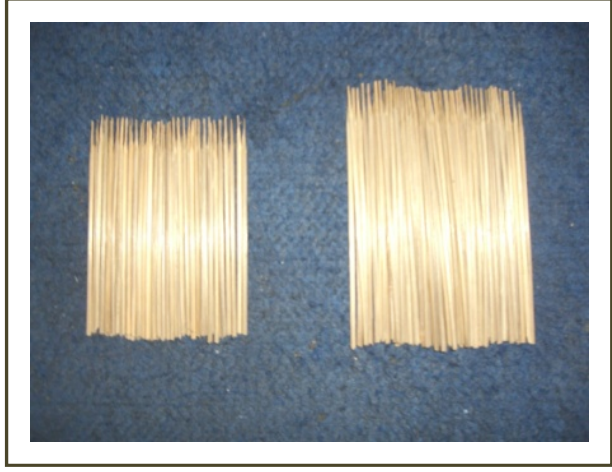

Gambar 10. Cerucuk dengan Panjang $15 \mathrm{~cm}$ dan $12,5 \mathrm{~cm}$

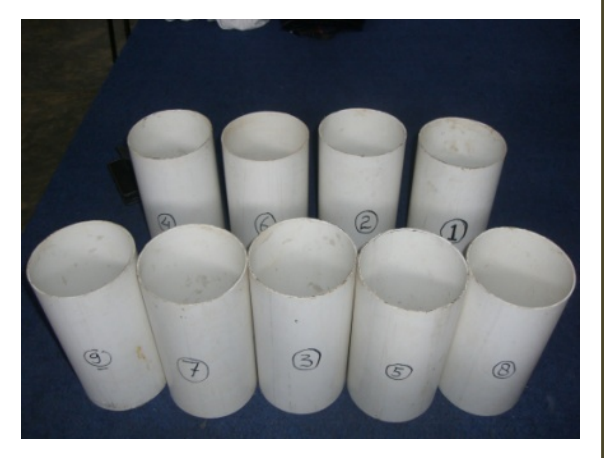

Gambar 12. Cetakan Silinder

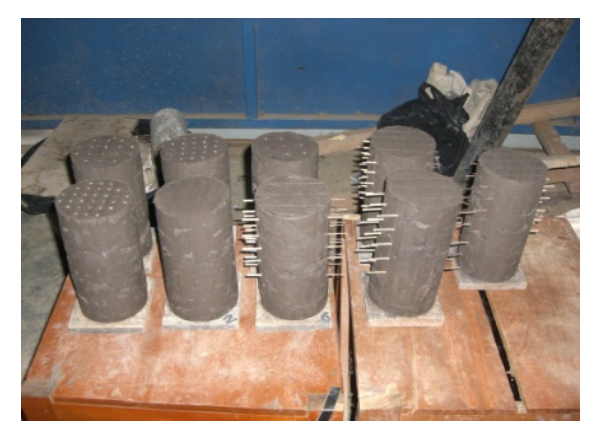

Gambar 14. Pemasangan Cerucuk dan Tanpa Cerucuk

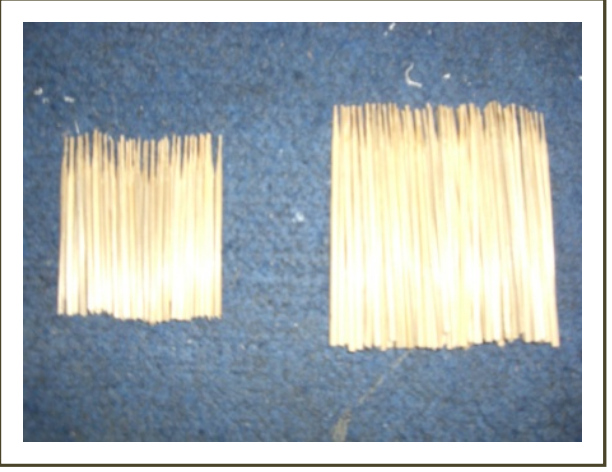

Gambar 11. Cerucuk dengan Panjang $10 \mathrm{~cm}$ dan $7.5 \mathrm{~cm}$

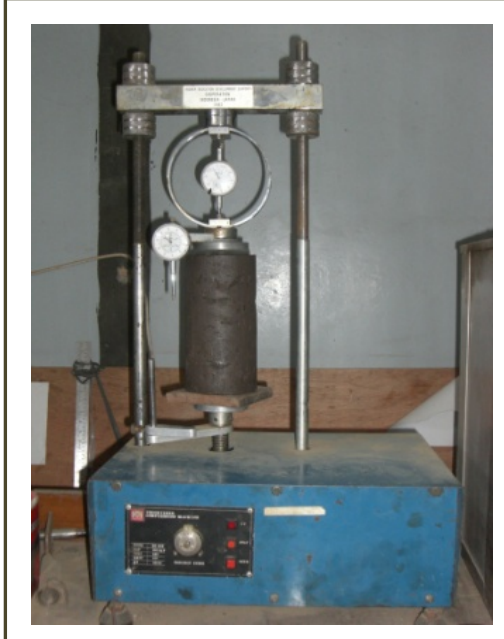

Gambar 13. Unconfined Strength Test

\section{HASIL DAN PEMBAHASAN}

Berdasarkan data dari hasil percobaan maka akan diperoleh nilai tegangan dari tanah lempung tersebut, dimana nilai tegangan tersebut menyatakan kekuatan tekan dari tanah lempung.

Contoh pengolahan data :

$$
\begin{array}{lll}
\varepsilon & =0,002 \\
A_{o} & =\pi r^{2} \\
& & =94,985 \mathrm{~cm}^{2}
\end{array}
$$




$$
\begin{array}{ll}
\text { Pembacaan arloji }(n) & =2 \\
\text { Beban }(P) & =n \mathrm{X}(\mathrm{kg}) \\
& =2 \times 0.51236 \\
& =1,025 \mathrm{~kg} \\
\text { Angka koreksi } & =1 /(1-\varepsilon) \\
\text { Luas terkoreksi }(A) & =1,002 \\
& =A_{o} \times \text { Angka Koreksi } \\
\text { Tegangan }(\sigma) & =94,985 \times 1,002 \\
& =95,136 \mathrm{~cm}^{2} \\
& =P / A\left(\mathrm{~kg} / \mathrm{cm}^{2}\right) \\
& =1,025 / 95,136 \\
& =0,0108 \mathrm{~kg} / \mathrm{cm}^{2}
\end{array}
$$

\subsection{Pemeriksaan Kuat Tekan Bebas pada Tanah Asli dan Remoulded}

\subsubsection{Model TC}

Perbandingan perilaku tegangan dan regangan antara model tanpa cerucuk pada tanah asli dan tanah remoulded diperlihatkan pada Gambar 15.

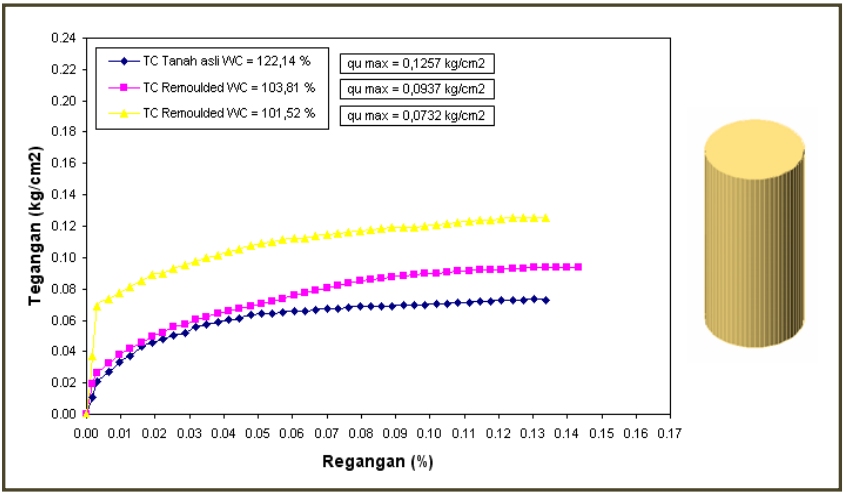

\section{Gambar 15. Stress - Strain TC pada Tanah Asli dan Remoulded}

\subsubsection{Model CV 150;1.60}

Perbandingan perilaku tegangan dan regangan antara model dengan panjang cerucuk vertikal $15 \mathrm{~cm}$ dan jarak antar cerucuk $1,60 \mathrm{~cm}(\mathrm{CV} 150 ; 1.60)$ pada tanah asli dan tanah remoulded diperlihatkan pada Gambar 16.

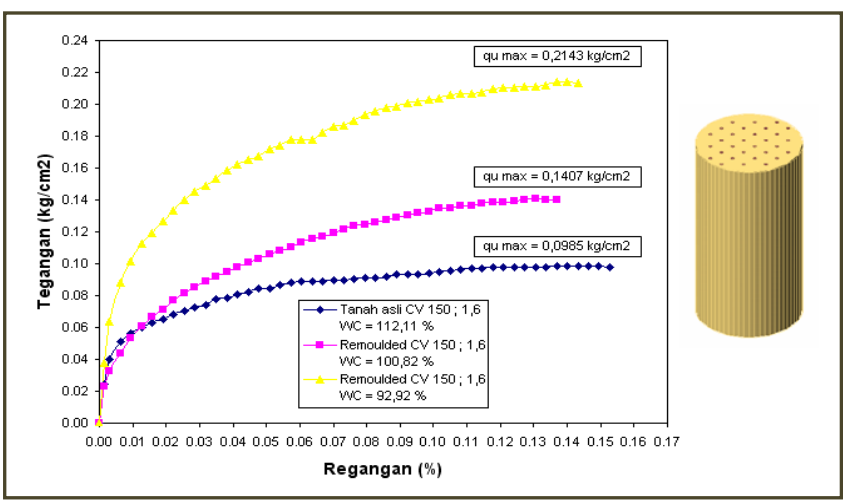

Gambar 16. Stress - Strain CV 150 ; 1.60 pada Tanah Asli dan Remoulded 


\subsubsection{Model CV $125 ; 1.83$}

Hasil dari pengujian ditampilkan pada grafik hubungan antara tegangan dan regangan. Gambar 17 memperlihatkan plot dari tegangan dan regangan untuk model dengan panjang cerucuk $12,5 \mathrm{~cm}$ dan jarak antar cerucuk $1,83 \mathrm{~cm}$.

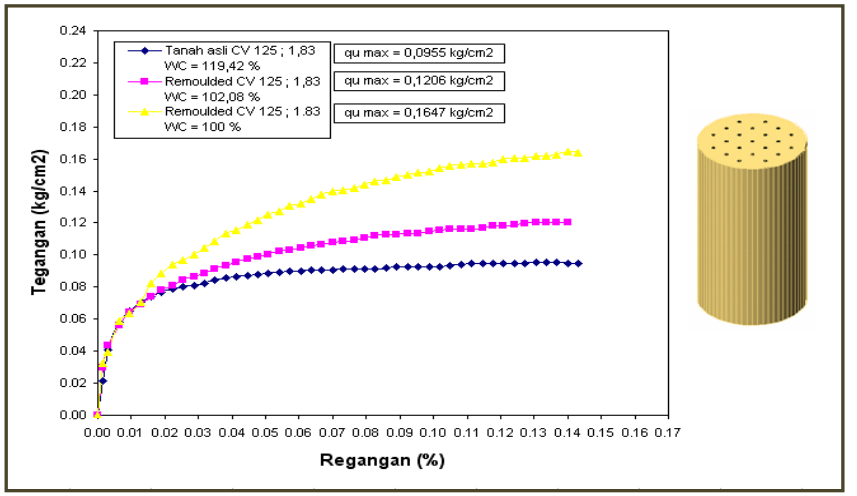

Gambar 17. Stress-Strain CV 125 ; 1.83 pada Tanah Asli dan Tanah Remoulded

\subsubsection{Model CV $100 ; 2.20$}

Perbandingan perilaku tegangan dan regangan antara model dengan panjang cerucuk vertikal $10 \mathrm{~cm}$ dan jarak antar cerucuk $2,20 \mathrm{~cm}(\mathrm{CV} 100 ; 2.20)$ pada tanah asli dan tanah remoulded diperlihatkan pada Gambar 18.

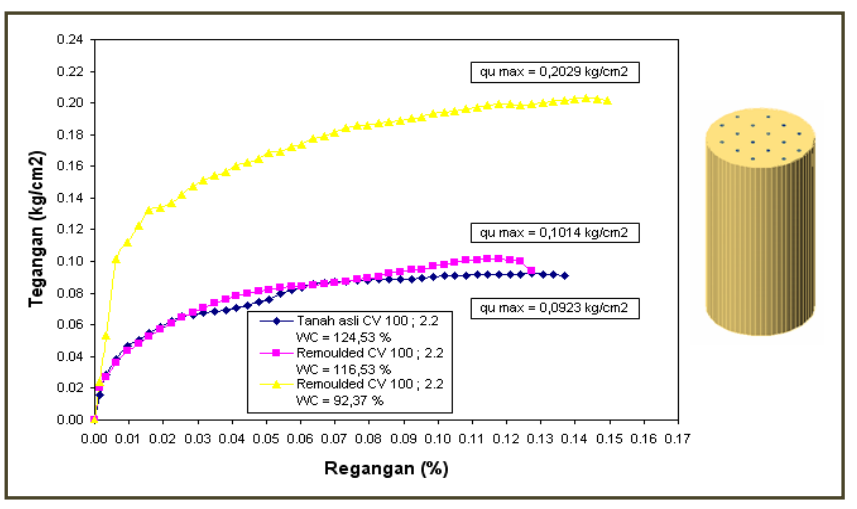

Gambar 18. Stress-Strain CV 100 ; 2.20 pada Tanah Asli dan Tanah Remoulded

\subsubsection{Model CV $75 ; 2.75$}

Perbandingan perilaku tegangan dan regangan antara model dengan panjang cerucuk vertikal 7,5 $\mathrm{cm}$ dan jarak antar cerucuk $2,75 \mathrm{~cm}(\mathrm{CV} 75 ; 2.75)$ pada tanah asli dan tanah remoulded diperlihatkan pada Gambar 19.

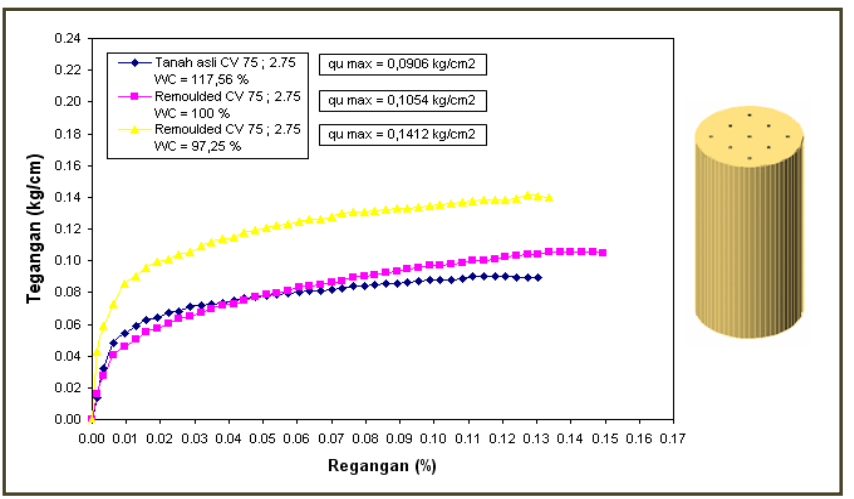

Gambar 19. Stress - Strain CV 75 ; 2.75 pada Tanah Asli dan Tanah Remoulded 


\subsubsection{Model CHS 150; 2.75}

Perbandingan perilaku tegangan dan regangan antara model dengan panjang cerucuk horizontal silang $15 \mathrm{~cm}$ dan jarak antar cerucuk $2,75 \mathrm{~cm}$ (CHS $150 ; 2.75$ ) pada tanah asli dan tanah remoulded diperlihatkan pada Gambar 20.

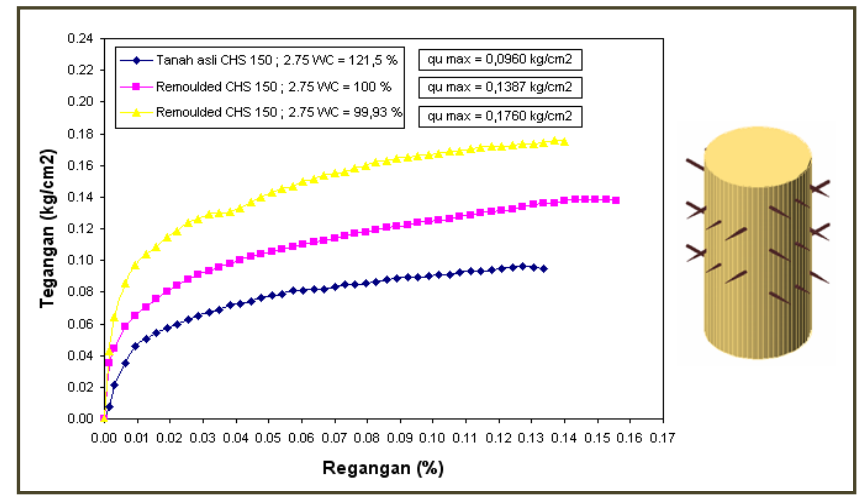

Gambar 20. Stress-Strain CHS 150; 2.75 pada Tanah Asli dan Tanah Remoulded

\subsubsection{Model CHS 125; 2.2}

Perbandingan perilaku tegangan dan regangan antara model dengan panjang cerucuk horizontal silang $12,5 \mathrm{~cm}$ dan jarak antar cerucuk $2,20 \mathrm{~cm}$ (CHS $125 ; 2.20$ ) pada tanah asli dan tanah remoulded diperlihatkan pada Gambar 21.

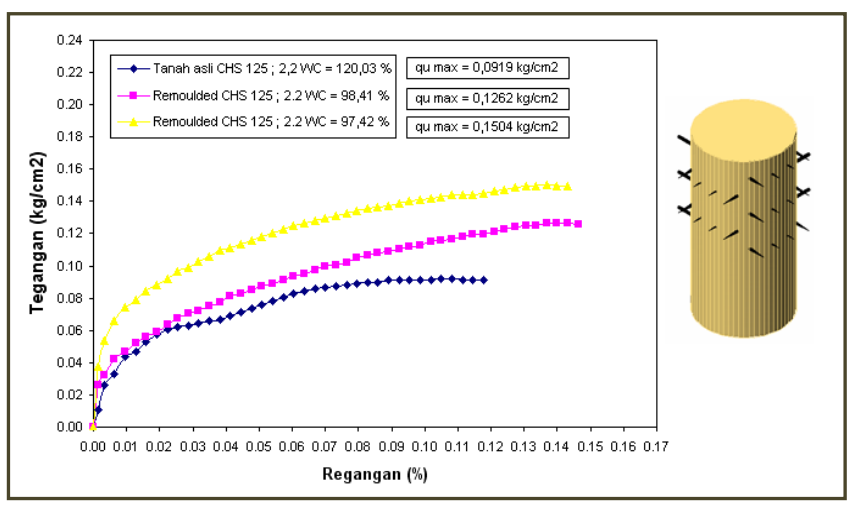

Gambar 21. Stress-Strain CHS 125; 2.20 pada Tanah Asli dan Tanah Remoulded

\subsubsection{Model CH $150 ; 2.75$}

Perbandingan perilaku tegangan dan regangan antara model dengan panjang cerucuk horizontal 15 $\mathrm{cm}$ dan jarak antar cerucuk $2,75 \mathrm{~cm}(\mathrm{CH} 150 ; 2.75)$ pada tanah asli dan tanah remoulded diperlihatkan pada Gambar 22.

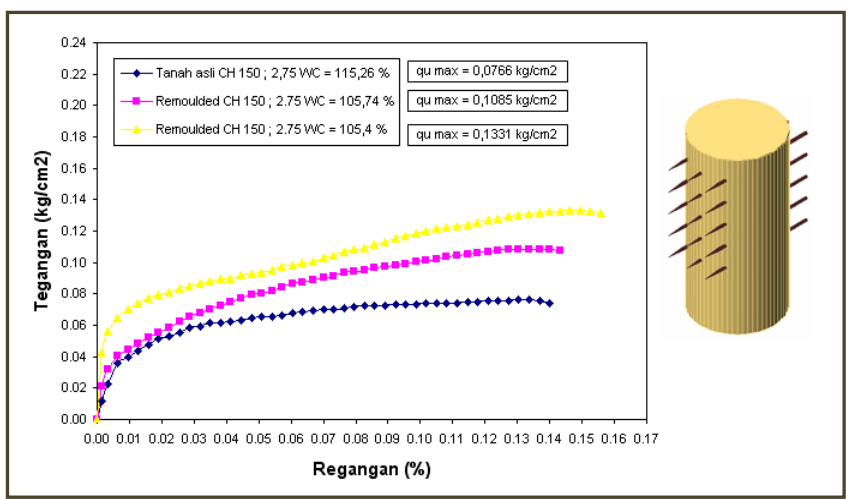

Gambar 22. Stress-Strain CH 150 ; 2.75 pada Tanah Asli dan Tanah Remoulded 


\subsubsection{Model CH $125 ; 2.20$}

Perbandingan perilaku tegangan dan regangan antara model dengan panjang cerucuk horizontal $12,5 \mathrm{~cm}$ dan jarak antar cerucuk $2,20 \mathrm{~cm}(\mathrm{CH} 125 ; 2.20)$ pada tanah asli dan tanah remoulded diperlihatkan pada Gambar 23.

Dari gambar terlihat bahwa tegangan pada tanah remoulded dengan WC $104.17 \%$ lebih besar dibandingkan dengan tegangan pada tanah remoulded dengan WC $106.08 \%$ dan pada tanah asli. Hal ini disebabkan karena kadar air pada tanah remoulded dengan WC $104.17 \%$ itu kecil dari kadar air yang lain.

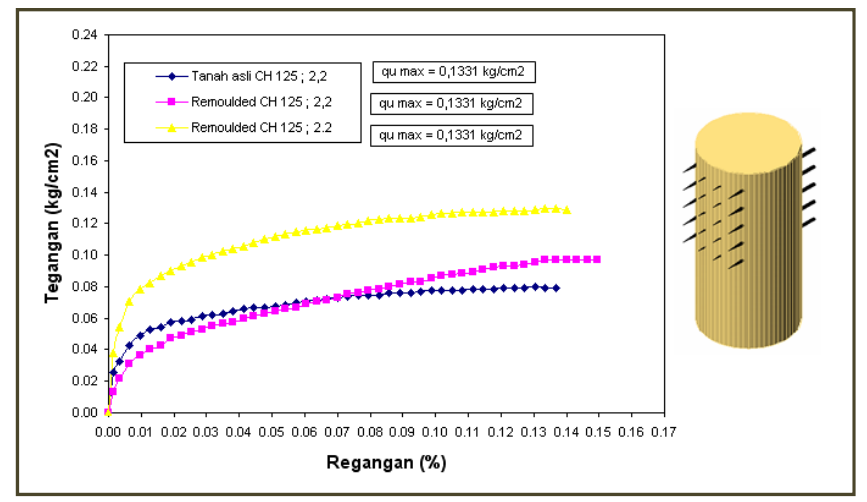

Gambar 23. Stress-Strain CH 125 ; 2.20 pada Tanah Asli dan Tanah Remoulded

Tabel 4. Kuat Tekan dari Model Masing-Masing Percobaan

\begin{tabular}{|l|c|c|c|}
\hline \multirow{2}{*}{ Model } & \multicolumn{3}{|c|}{ Kuat Tekan (kg/cm2) } \\
\cline { 2 - 4 } & Tanah Asli & Remoulde I & Remoulded II \\
\hline TC & 0,0732 & 0,0937 & 0,1257 \\
\hline CV $150 ; 1,60$ & 0,0985 & 0,1407 & 0,2143 \\
\hline CV $125 ; 1,83$ & 0,0955 & 0,1206 & 0,1647 \\
\hline CV $100 ; 2,20$ & 0,0923 & 0,1014 & 0,2029 \\
\hline CV $75 ; 2,75$ & 0,0906 & 0,1054 & 0,1412 \\
\hline CHS $150 ; 2,75$ & 0,0960 & 0,1387 & 0,176 \\
\hline CHS $125 ; 2,20$ & 0,0919 & 0,1262 & 0,1504 \\
\hline CH $150 ; 2,75$ & 0,0766 & 0,1085 & 0,1331 \\
\hline CH $125 ; 2,20$ & 0,0797 & 0,0972 & 0,1299 \\
\hline
\end{tabular}

\section{KESIMPULAN DAN SARAN}

\subsection{Kesimpulan}

Dari hasil pengujian yang telah dilakukan pada tanah lempung dengan model tanpa cerucuk dan menggunakan cerucuk didapatkan kesimpulan sebagai berikut :

1. Tanah asli dengan cerucuk horizontal dan bersilang, konfigurasi bersilang lebih kuat dari horizontal saja. Jarak makin pendek kekuatan makin besar.

2. Tanah remolded dengan cerucuk horizontal dan bersilang, konfigurasi bersilang lebih kuat dari horizontal. Jarak makin panjang kekuatan makin besar.

3. Tanah asli dengan cerucuk vertikal, makin panjang dan rapat cerucuk maka kekuatan makin tinggi. 
4. Tanah remolded dengan cerucuk vertikal, makin panjang cerucuk dan rapat kekuatan makin tinggi, diikuti dengan kadar air makin rendah.

5. Kekuatan cerucuk vertikal lebih baik dari horizontal, kadar air makin rendah kekuatan makin tinggi.

\subsection{Saran}

Untuk hasil yang lebih baik, maka dianjurkan dengan kadar air seragam untuk semua tipe pengujian dan memvariasikan kadar air terhadap konfigurasi cerucuk tertentu.

\section{DAFTAR PUSTAKA}

Arya, I. Wayan, (2002), Pengaruh Penambahan Cerucuk terhadap Peningkatan Kuat Geser Tanah Lunak pada Pemodelan di Laboratorium, Jurusan Teknik Sipil, Fakultas Teknik, Institut Teknologi Surabaya,Surabaya.

Hardiyatmo, H. C., (2002), Teknik Fondasi, PERUM FT - UGM, Yogyakarta.

Jemmy Effendy \& Wijaya Gunawan, (1999), Peningkatan Daya Dukung Pondasi Dangkal dengan Menggunakan Cerucuk, Jurusan Teknik Sipil, Fakultas Teknik, Uniersitas Kristen Petra, Surabaya.

Mochtar, Endah dan Indrasurya, (1995), Mekanika Tanah (Prinsip-Prinsip Rekayasa Geoteknis) Braja M. Das, Jilid I, Erlangga, Surabaya.

Penuntun Praktikum Mekanika Tanah, Universitas Andalas, Padang.

Rudy Cahyadi \& Alvin Eriecson. W., (2002), Pengaruh Cerucuk terhadap Kekuatan Geser Tanah Lempung, Jurusan Teknik Sipil, Fakultas Teknik, Uniersitas Kristen Petra, Surabaya.

Sunggono, (1984), Mekanika Tanah, Nova, Bandung.

Widaja, Steven \& Louis Edward H., (2002), Penggunaan Cerucuk pada Tanah Pasir untuk Mengurangi Tekanan Tanah Aktif pada Struktur Penahan Tanah, Jurusan Teknik Sipil, Fakultas Teknik, Uniersitas Kristen Petra, Surabaya. 
Peningkatan Kekuatan Geser Tanah dengan Menggunakan Cerucuk

38 | JURNAL REKAYASA SIPIL 